\title{
Telmisartan and cardioprotection
}

\author{
This article was published in the following Dove Press journal: \\ Vascular Health and Risk Management \\ I4 November 201 I \\ Number of times this article has been viewed
}

\author{
Philippe R Akhrass \\ Samy I McFarlane \\ State University of New York, \\ Downstate Medical Center, \\ Brooklyn, NY, USA
}

Correspondence: Samy I McFarlane State University of New York, Downstate Medical Center, Kings County Hospital Center, 450 Clarkson Avenue, Box 50, Brooklyn, NY I 1203, USA Tel + I 71827037 II

Fax +I 7182706358

Email samy.mcfarlane@downstate.edu
Abstract: Cardiovascular risk reduction has been the target of several large clinical trials in the last decade. As the activation of the renin-angiotensin-aldosterone system (RAAS) plays a central role in the pathogenesis of atherosclerosis and cardiovascular disease, RAAS blockade has been suggested to be among the most efficient cardioprotective interventions, as revealed with the angiotensin converting enzyme (ACE) inhibitors trials. The angiotensin receptor blockers' (ARBs) efficacy in lowering blood pressure has been very well established. Telmisartan is however the first ARB to show a promising role in reducing cardiovascular risk in high-risk patients. This article will highlight the role of telmisartan in cardioprotection, underlying specifically the results of two major randomized controlled trials: ONTARGET (ONgoing Telmisartan Alone and in combination with Ramipril Global Endpoint Trial) and TRANSCEND (Telmisartan Randomized AssessmeNt Study in aCE-iNtolerant subjects with cardiovascular Disease).

Keywords: telmisartan, cardioprotection, ONTARGET, TRANSCEND

\section{Introduction}

Although death rates from cardiovascular disease have significantly declined over the last 10 years, the burden of the disease remains very high. In 2006, cardiovascular disease was responsible for $34.3 \%(831,272)$ of all deaths in the US. The estimated direct and indirect cost of cardiovascular disease for 2010 is US\$503.2 billion. ${ }^{1}$ A great deal of effort has been directed toward treating cardiovascular and controlling its traditional risk factors.

The chronic activation of the renin-angiotensin-aldosterone system (RAAS) plays a central role in the pathogenesis of atherosclerosis, hypertension, left ventricular hypertrophy (LVH), myocardial infarction, and heart failure. ${ }^{2}$ The inhibition of the RAAS can be achieved by inhibiting the angiotensin-converting enzyme (ACE) or by directly blocking the angiotensin receptors. The use of ACE inhibitors is known to reduce mortality and cardiovascular risk in high-risk patients. ${ }^{3}$ On the other hand, the use of angiotensin receptor blockers (ARBs) is well established for the treatment of hypertension and in patients with heart failure or following myocardial infarction. Until recently, their role in cardioprotection remained unclear.

This review article highlights the results of the clinical trials examining the efficacy of the ARB telmisartan across the cardiovascular spectrum (Table 1). The cardioprotective role of telmisartan is further discussed in the review of the ONTARGET (ONgoing Telmisartan Alone and in combination with Ramipril Global Endpoint Trial) and TRANSCEND (Telmisartan Randomized AssessmeNt Study in aCE-iNtolerant subjects with cardiovascular Disease) studies. 


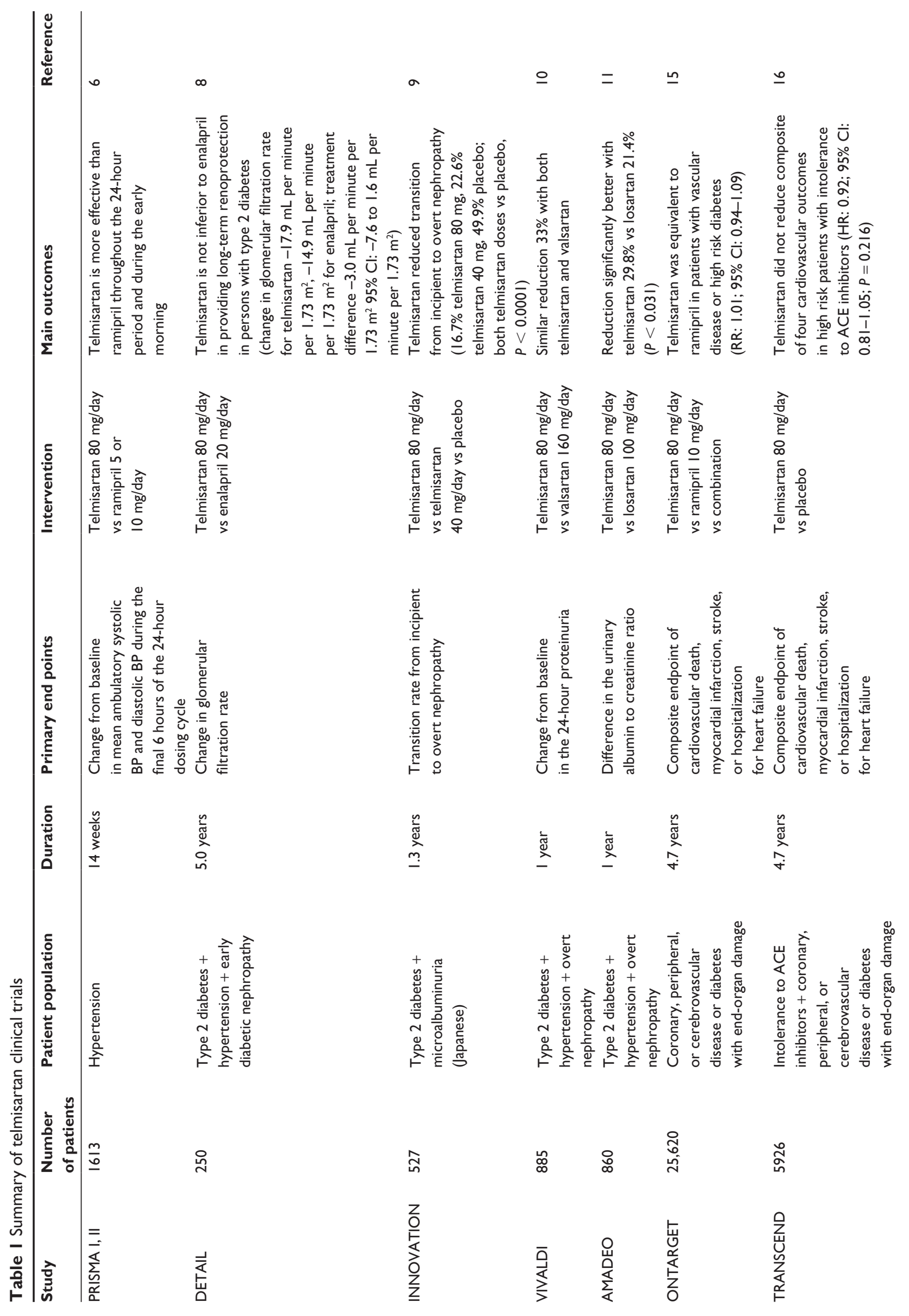




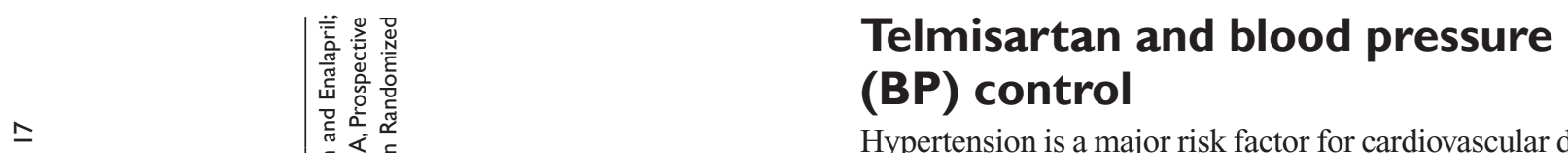

Hypertension is a major risk factor for cardiovascular disease. The ARBs are broadly effective in lowering BP with relatively few side effects, notably the absence of cough and angioedema, which represents their major advantage over ACE inhibitors. Telmisartan is an ARB that was approved by the Food and Drug Administration (FDA) for the treatment of hypertension in November 1998, and is proven to provide efficient and lasting BP control when compared to other agents. In one meta-analysis of 28 randomized controlled trials involving 5157 patients, telmisartan had a superior BP control over different ACE inhibitors (enalapril, ramipril, and perindopril), fewer drugrelated adverse events, and better tolerability in hypertensive patients. ${ }^{4}$ In another meta-analysis of eleven studies involving 1832 patients, telmisartan resulted in a significant reduction in diastolic BP (weighted mean difference $1.52 \mathrm{mmHg}$; 95\% confidence interval [CI]: 0.85-2.19) and systolic BP (2.77 mmHg; 95\% CI: 1.90-3.63) when compared with losartan, as well as a significant reduction in 24-hour mean ambulatory BP. ${ }^{5}$

Furthermore, evidence suggests that cardiovascular risk may be subject to circadian variation, with peak morning incidence of myocardial infarction and stroke correlating with the early morning BP surge. Antihypertensive agents differ in their ability to control 24-hour BP. Ideally antihypertensive therapy should maintain control of BP throughout the 24-hour dosing cycle and especially in the last 6 hours of the cycle. In two prospective trials, PRISMA I and II (Prospective, Randomized Investigation of the Safety and efficacy of Micardis vs ramipril using Ambulatory BP monitoring) patients with essential hypertension were randomized to receive telmisartan $80 \mathrm{mg} /$ day $(\mathrm{n}=802)$ or ramipril $5 \mathrm{mg} /$ day or $10 \mathrm{mg} /$ day $(\mathrm{n}=811)$ for 14 weeks. ${ }^{6}$ The primary endpoint was the change from baseline in mean ambulatory systolic BP and diastolic BP during the final 6 hours of the 24-hour dosing cycle. After 14 weeks, telmisartan was more effective than ramipril in controlling BP throughout the 24-hour period and during the early morning (mean systolic/ diastolic $-4.1 /-3.0 \mathrm{mmHg}, P<0.0001)$. These results may be attributable to the long effect duration of telmisartan, which is sustained throughout the 24-hour dosing period. ${ }^{6}$

\section{Telmisartan, urinary protein excretion, and cardiovascular risk}

The importance of urinary protein excretion as a cardiovascular risk factor has been established by a number of large studies. The HOPE (Heart Outcomes Prevention 
Evaluation) study, which included 9043 high-risk patients, showed a correlation between the degree of albuminuria and cardiovascular risk, both in individuals with and without diabetes. After adjustment for other risk factors, the relative risk (RR) of major cardiovascular events (cardiovascular death, myocardial infarction, or stroke) associated with microalbuminuria was 1.83 (95\% CI: 1.64-2.05). ${ }^{7} \mathrm{ACE}$ inhibitors are well known to reduce microalbuminuria and improve renal function. In the DETAIL (Diabetics Exposed to Telmisartan and Enalapril) trial, telmisartan was not inferior to the ACE inhibitor enalapril in preventing the progression of renal dysfunction, measured as the decline in the glomerular filtration rate in patients with diabetes. ${ }^{8}$ Furthermore, in the INNOVATION (Incipient to Overt: Angiotensin II Blocker, Telmisartan, Investigation on Type 2 Diabetic Nephropathy) study, 527 diabetic hypertensive and normotensive Japanese patients with microalbuminuria were randomized to telmisartan $40 \mathrm{mg}$, telmisartan $80 \mathrm{mg}$, or placebo. ${ }^{9}$ The transition to overt diabetic nephropathy was dose dependent and significantly lower in the telmisartan $80 \mathrm{mg}$ and telmisartan $40 \mathrm{mg}$ groups compared with placebo (16.7\% and $22.6 \%$ vs $49.9 \%$, respectively; $P<0.0001)$ over a 30-month follow up period. Telmisartan also reduced transition to overt nephropathy in normotensive patients, suggesting a BP independent effect. ${ }^{9}$ In the VIVALDI (inVestIgate the efficacy of telmisartan versus VALsartan in hypertensive type 2 DIabetic) trial, telmisartan $80 \mathrm{mg} /$ day and valsartan $160 \mathrm{mg} /$ day produced similar reductions in 24-hour urinary protein excretion rates by $33 \%$ after 12 months of treatment in diabetic patients with hypertension and overt nephropathy. ${ }^{10}$ It is thought that their renoprotective benefit in VIVALDI, was solely due to the antihypertensive effect. However, in the AMADEO (A comparison of telMisartan versus losArtan in hypertensive type 2 DiabEtic patients with Overt nephropathy) trial, telmisartan $80 \mathrm{mg} /$ day was superior to losartan $100 \mathrm{mg}$ /day in terms of renoprotective properties. Telmisartan showed a greater reduction in the urinary albumin to creatinine ratio than the losartan $(29.8 \%$ and $21.4 \%$, respectively; $P<0.031$ ), despite similar BP reduction. ${ }^{11}$

\section{Telmisartan and prevention of cardiovascular disease in high-risk patients}

Multiple randomized controlled trials demonstrated reduction of mortality and hospital admissions in patients with heart failure when treated with an ARB. ${ }^{12}$ When compared to atenolol, ARBs decreased vascular events in patients with hypertension and LVH. ${ }^{13}$ In addition, ARBs were comparable to ACE inhibitors in patients with acute myocardial infarction and heart failure in terms of all-cause mortality. ${ }^{14}$

The ONTARGET trial is a landmark large trial that established the role of ARBs in reducing cardiovascular events in high-risk patients. ${ }^{15}$ ONTARGET studied patients with coronary, peripheral, or cerebrovascular disease or diabetes with end-organ damage. Patients with congestive heart failure were excluded. Participants who could not tolerate ACE inhibitors were studied in a parallel trial with telmisartan vs placebo. In ONTARGET, 25,620 patients were randomized to receive telmisartan $80 \mathrm{mg} /$ day, ramipril $10 \mathrm{mg} /$ day, or the combination of both drugs, and were followed for 56 months. The primary outcome was a composite of death from cardiovascular causes, myocardial infarction, stroke, or hospitalization for heart failure. Telmisartan was equivalent to ramipril for the primary outcome (telmisartan $16.7 \%$, ramipril $16.5 \%$, RR: 1.01; 95\% CI: 0.94-1.09). Telmisartan caused lower rates of cough $(1.1 \%$ vs $4.2 \% ; P<0.001)$ and angioedema $(0.1 \%$ vs $0.3 \% ; P=0.01)$ and a higher rate of hypotensive symptoms (2.6\% vs $1.7 \% ; P<0.001)$ when compared with ramipril. The combination of the two drugs did not improve outcomes and was associated with more adverse events including a significantly higher rate of discontinuation $(29.3 \%$ vs $24.5 \%$ with ramipril and $23.0 \%$ with telmisartan; $P<0.001)$. These findings suggest that RAAS blockade with either telmisartan or ramipril is optimal for cardiovascular risk reduction, and that telmisartan is comparable to ramipril in patients with vascular disease or high risk diabetes, with fewer cough and angioedema events.

In the TRANSCEND trial, 5926 high-risk patients intolerant to ACE inhibitors, but otherwise similar to ONTARGET population, were randomized to receive telmisartan $80 \mathrm{mg}$ /day or placebo. ${ }^{16}$ After 56 months, telmisartan did not reduce a composite endpoint of cardiovascular death, myocardial infarction, stroke, or hospitalization for heart failure in patients with cardiovascular disease or diabetes with end-organ damage (telmisartan $15.7 \%$, placebo $17 \%$, hazard ratio [HR]: 0.92 ; 95\% CI: $0.81-1.05, P=0.216$ ). However, telmisartan reduced the secondary composite outcome of cardiovascular death, myocardial infarction, and stroke (telmisartan 13\%, placebo 14.8\%; odds ratio [OR]: $0.86 ; 95 \% \mathrm{CI}: 0.74-1.00 ; P=0.045)$, which was the HOPE composite outcome. In contrast with the HOPE study, a neutral effect of telmisartan on hospitalizations for heart failure was observed, and may be due to a higher use of diuretics $(32.8 \%)$ and $\beta$-blockers $(57.2 \%)$ in the placebo arm of TRANSCEND, in contrast with $15.2 \%$ and $39.8 \%$, 
respectively in the placebo arm of the HOPE trial a decade ago. Therefore TRANSCEND validates the role of ARBs in reducing cardiovascular risk in high-risk patients and does not contradict ONTARGET.

PRoFESS (PReventiOn regimen For Effectively avoiding Second Strokes) is another large randomized controlled trial that enrolled 20,322 patients older than 50 years of age who had an ischemic stroke in the previous 120 days and were clinically and neurologically stable. ${ }^{17}$ Patients were randomized to receive telmisartan $80 \mathrm{mg}$ /day vs placebo, and were followed for 2.5 years. The primary outcome was recurrent stroke, and secondary outcomes were major cardiovascular events (death from cardiovascular causes, recurrent stroke, myocardial infarction, or new or worsening heart failure) and new-onset diabetes. Therapy with telmisartan initiated soon after an ischemic stroke and continued for 2.5 years did not significantly lower the rate of recurrent stroke, major cardiovascular events, or diabetes. Post hoc analyses showed that from 6 months on, recurrent stroke rate was lower in the telmisartan group (5.3\% vs $6.0 \%$; HR: 0.88 ; 95\% CI: 0.78-0.99). This finding suggests a time-dependent benefit of telmisartan and that the trial duration may have been too short to detect a difference.

In the NAVIGATOR (Nateglinide and Valsartan in Impaired Glucose Tolerance Outcomes Research) trial, valsartan, as compared with placebo, did not significantly reduce the incidence of cardiovascular outcomes among patients with impaired glucose tolerance and cardiovascular disease or risk factors (8.1\% vs 8.1\%; HR: 0.99; 95\% CI: 0.86-1.14; $P=0.85){ }^{18}$

\section{Telmisartan and effects on left ventricular mass}

ACE inhibitors are known to reduce LVH. The effects of telmisartan and ramipril on LVH were studied in a subsequent analysis of the ONTARGET and TRANSCEND trials. ${ }^{19}$ In TRANSCEND, the prevalence of LVH at entry was $12.7 \%$. After 5 years of therapy, it was reduced to $9.9 \%$ in the telmisartan group, when compared to $12.8 \%$ in the placebo group (OR: 0.79; 95\% CI: 0.68-0.91; $P=0.0017$ ). Furthermore, telmisartan reduced new-onset LVH by $37 \%$ when compared with placebo. However in patients with LVH at entry, regression of LVH was similar in both groups. In ONTARGET, telmisartan showed a trend to be slightly, but not significantly, more effective than ramipril in reducing LVH (OR: 0.92; 95\% CI: $0.83-1.01 ; P=0.07)$. The combination of the telmisartan and ramipril did not provide any additional benefit compared to ramipril (OR: 0.93; 95\% CI: 0.84-1.02; $P=0.12$ ).
New-onset LVH was associated with a higher risk of primary outcome during follow-up (HR: 1.77; 95\% CI: 1.50-2.07). Greater LVH regression with an ARB compared with an ACE inhibitor was observed, and might be explained by the overactivation of angiotensin II type 2 receptor after blocking the effects of angiotensin II at the angiotensin II type 1 receptor by ARBs.

\section{Telmisartan and atrial fibrillation}

Evidence is emerging for a role of RAAS in the pathophysiology of atrial fibrillation and a possible role for ACE inhibitors and ARBs in primary and secondary prevention of atrial fibrillation. A meta-analysis of 23 randomized controlled trials involving 87,048 patients showed that RAAS inhibition reduced the OR for atrial fibrillation by $33 \%(P<0.00001)$. In primary prevention, RAAS inhibition was effective in patients with heart failure, hypertension, and LVH but not in post-myocardial infarction patients. In secondary prevention, the addition of RAAS inhibition to antiarrhythmic drugs and medical therapy was also effective. ${ }^{20}$ In the secondary outcomes of the ONTARGET trial, new-onset atrial fibrillation was similar in the telmisartan group (6.9\%) and the ramipril group (6.5\%) (RR: 0.97; 95\% CI: 0.86-1.09), as well as with the combination of both drugs. ${ }^{15}$ These data suggest a certain role for RAAS inhibition in the prevention of atrial fibrillation, but further large trials are needed to address this specific role.

\section{Telmisartan and prevention of diabetes mellitus}

RAAS blockade may play a role in the prevention of diabetes. In a post hoc analysis of the HOPE trial, ramipril was associated with a $34 \%$ reduction in the risk of new-onset diabetes (RR: 0.66 ; 95\% CI: $0.51-0.85 ; P<0.001$ ) when compared with placebo. ${ }^{21}$ However in the DREAM (Diabetes REduction Assessment with ramipril and rosiglitazone Medication) trial, ramipril did not reduce the primary outcome of diabetes or death in patients with impaired fasting glucose or impaired glucose tolerance at low risk for cardiovascular events, however follow-up was for 3 years only. ${ }^{22}$ On the other hand, in a meta-analysis of 13 studies involving approximately 67,000 patients, ACE inhibitors and ARBs reduced significantly new-onset diabetes mellitus in patients with hypertension or other cardiovascular risk factors with a RR of 0.79 (95\% CI: 0.74-0.85) for ACE inhibitors and 0.78 (95\% CI: $0.73-0.84)$ for ARBs. ${ }^{23}$

In the ONTARGET trial, incidence of new-onset diabetes was similar in the telmisartan and ramipril groups. ${ }^{15}$ 
In PRoFESS trial, telmisartan did not prevent new-onset diabetes in patients with ischemic stroke. ${ }^{17}$ In contrast, in the TRANSCEND trial, telmisartan reduced significantly the secondary outcome of new-onset diabetes compared to placebo (HR: 0.85; 95\% CI: $0.71-1.02 ; P=0.081$ ). ${ }^{16}$ Most recently in the NAVIGATOR trial, valsartan reduced by $14 \%$ the incidence of diabetes among patients with impaired glucose tolerance and cardiovascular disease or risk factors. ${ }^{18}$

Finally, accumulating evidence suggests that telmisartan is a partial agonist of the peroxisome proliferator activated receptor-gamma (PPAR- $\gamma$ ). ${ }^{24}$ Multiple in vitro and animal studies showed that the activation of this pathway is important in dyslipidemia, metabolic syndrome, and vascular disease. ${ }^{25-27}$ Although clinical data is limited, the pleiotropic effect of telmisartan as a selective PPAR- $\gamma$ modulator may play an important role in the prevention and treatment of diabetes and cardiovascular disease..$^{28,29}$

\section{Conclusion}

Telmisartan is an ARB approved by the FDA for the treatment of hypertension since November 1998. In October 2009, based on the results from the ONTARGET trial, telmisartan was the first ARB to be granted FDA approval for reduction of cardiovascular risk in high-risk patients unable to take ACE inhibitors. Within the RAAS inhibition agents, telmisartan is characterized by a long duration of effect providing 24-hour BP control. Although providing similar renoprotective effects, telmisartan was associated with a better reduction of protein excretion than valsartan. In addition, evidence is emerging for a potential role of telmisartan and other ARBs in the prevention of new-onset diabetes and the prevention of atrial fibrillation. Finally, based on the ONTARGET and TRANSCEND studies, RAAS blockade with telmisartan is shown to provide optimal cardioprotection in high-risk patients, along with a good tolerance profile.

\section{Disclosure}

The authors report no conflicts of interest in this work.

\section{References}

1. Lloyd-Jones D, Adams RJ, Brown TM, et al. Heart disease and stroke statistics - 2010 update: a report from the American Heart Association. Circulation. 2010;121(7):e46-e215.

2. McFarlane SI, Kumar A, Sowers JR. Mechanisms by which angiotensin-converting enzyme inhibitors prevent diabetes and cardiovascular disease. Am J Cardiol. 2003;91(12A):30H-37H.

3. Danchin N, Cucherat M, Thuillez C, Durand E, Kadri Z, Steg PG. Angiotensin-converting enzyme inhibitors in patients with coronary artery disease and absence of heart failure or left ventricular systolic dysfunction: an overview of long-term randomized controlled trials. Arch Intern Med. 2006;166(7):787-796.
4. Zou Z, Xi GL, Yuan HB, Zhu QF, Shi XY. Telmisartan versus angiotension-converting enzyme inhibitors in the treatment of hypertension: a meta-analysis of randomized controlled trials. J Hum Hypertens. 2009;23(5):339-349.

5. Xi GL, Cheng JW, Lu GC. Meta-analysis of randomized controlled trials comparing telmisartan with losartan in the treatment of patients with hypertension. Am J Hypertens. 2008;21(5):546-552.

6. Williams B, Lacourciere Y, Schumacher H, Gosse P, Neutel JM. Antihypertensive efficacy of telmisartan vs ramipril over the 24-h dosing period, including the critical early morning hours: a pooled analysis of the PRISMA I and II randomized trials. J Hum Hypertens. 2009;23(9):610-619.

7. Gerstein HC, Mann JF, Yi Q, et al. Albuminuria and risk of cardiovascular events, death, and heart failure in diabetic and nondiabetic individuals. JAMA. 2001;286(4):421-426.

8. Barnett AH, Bain SC, Bouter P, et al. Angiotensin-receptor blockade versus converting-enzyme inhibition in type 2 diabetes and nephropathy. N Engl J Med. 2004;351(19):1952-1961.

9. Makino H, Haneda M, Babazono T, et al. Prevention of transition from incipient to overt nephropathy with telmisartan in patients with type 2 diabetes. Diabetes Care. 2007;30(6):1577-1578.

10. Galle J, Schwedhelm E, Pinnetti S, Boger RH, Wanner C. Antiproteinuric effects of angiotensin receptor blockers: telmisartan versus valsartan in hypertensive patients with type 2 diabetes mellitus and overt nephropathy. Nephrol Dial Transplant. 2008;23(10):3174-3183.

11. Bakris G, Burgess E, Weir M, Davidai G, Koval S. Telmisartan is more effective than losartan in reducing proteinuria in patients with diabetic nephropathy. Kidney Int. 2008;74(3):364-369.

12. Granger CB, McMurray JJ, Yusuf S, et al. Effects of candesartan in patients with chronic heart failure and reduced left-ventricular systolic function intolerant to angiotensin-converting-enzyme inhibitors: the CHARM-Alternative trial. Lancet. 2003;362(9386):772-776.

13. Dahlof B, Devereux RB, Kjeldsen SE, et al. Cardiovascular morbidity and mortality in the Losartan Intervention For Endpoint reduction in hypertension study (LIFE): a randomized trial against atenolol. Lancet. 2002;359(9311):995-1003.

14. McMurray JJ, Ostergren J, Swedberg K, et al. Effects of candesartan in patients with chronic heart failure and reduced left-ventricular systolic function taking angiotensin-converting-enzyme inhibitors: the CHARM-Added trial. Lancet. 2003;362(9386):767-771.

15. Yusuf S, Teo KK, Pogue J, et al. Telmisartan, ramipril, or both in patients at high risk for vascular events. N Engl J Med. 2008;358(15):1547-1559.

16. Yusuf S, Teo K, Anderson C, et al. Effects of the angiotensin-receptor blocker telmisartan on cardiovascular events in high-risk patients intolerant to angiotensin-converting enzyme inhibitors: a randomised controlled trial. Lancet. 2008;372(9644):1174-1183.

17. Yusuf S, Diener HC, Sacco RL, et al. Telmisartan to prevent recurrent stroke and cardiovascular events. N Engl J Med. 2008;359(12):1225-1237.

18. McMurray JJ, Holman RR, Haffner SM, et al. Effect of valsartan on the incidence of diabetes and cardiovascular events. $N$ Engl J Med. 2010;362(16):1477-1490.

19. Verdecchia P, Sleight P, Mancia G, et al. Effects of telmisartan, ramipril, and their combination on left ventricular hypertrophy in individuals at high vascular risk in the Ongoing Telmisartan Alone and in Combination With Ramipril Global End Point Trial and the Telmisartan Randomized Assessment Study in ACE Intolerant Subjects With Cardiovascular Disease. Circulation. 2009;120(14):1380-1389.

20. Schneider MP, Hua TA, Bohm M, Wachtell K, Kjeldsen SE, Schmieder RE. Prevention of atrial fibrillation by Renin-Angiotensin system inhibition a meta-analysis. J Am Coll Cardiol. 2010;55(21):2299-2307.

21. Yusuf S, Gerstein H, Hoogwerf B, et al. Ramipril and the development of diabetes. JAMA. 2001;286(15):1882-1885.

22. Bosch J, Yusuf S, Gerstein HC, et al. Effect of ramipril on the incidence of diabetes. N Engl J Med. 2006;355(15):1551-1562.

23. McCall KL, Craddock D, Edwards K. Effect of angiotensin-converting enzyme inhibitors and angiotensin II type 1 receptor blockers on the rate of new-onset diabetes mellitus: a review and pooled analysis. Pharmacotherapy. 2006;26(9):1297-1306. 
24. Schupp M, Janke J, Clasen R, Unger T, Kintscher U. Angiotensin type 1 receptor blockers induce peroxisome proliferator-activated receptorgamma activity. Circulation. 2004;109(17):2054-2057.

25. Benson SC, Pershadsingh HA, Ho CI, et al. Identification of telmisartan as a unique angiotensin II receptor antagonist with selective PPARgamma-modulating activity. Hypertension. 2004;43(5):993-1002.

26. Schupp M, Clemenz M, Gineste R, et al. Molecular characterization of new selective peroxisome proliferator-activated receptor gamma modulators with angiotensin receptor blocking activity. Diabetes. 2005;54(12):3442-3452.
27. Fujisaka S, Usui I, Kanatani Y, et al. Telmisartan improves insulin resistance and modulates adipose tissue macrophage polarization in high-fat-fed mice. Endocrinology. 2011;152(5):1789-1799.

28. Watanabe M, Inukai K, Sumita T, et al. Effects of telmisartan on insulin resistance in Japanese type 2 diabetic patients. Intern Med. 2010;49(17):1843-1847.

29. Marketou ME, Kontaraki JE, Tsakountakis NA, et al. Differential effect of telmisartan and amlodipine on monocyte chemoattractant protein-1 and peroxisome proliferator-activated receptor-gamma gene expression in peripheral monocytes in patients with essential hypertension. $\mathrm{Am} \mathrm{J}$ Cardiol. 2011;107(1):59-63.

\section{Publish your work in this journal}

Vascular Health and Risk Management is an international, peerreviewed journal of therapeutics and risk management, focusing on concise rapid reporting of clinical studies on the processes involved in the maintenance of vascular health; the monitoring, prevention and treatment of vascular disease and its sequelae; and the involvement of metabolic disorders, particularly diabetes. This journal is indexed on PubMed Central and MedLine. The manuscript management system is completely online and includes a very quick and fair peer-review system, which is all easy to use. Visit http://www.dovepress.com/ testimonials.php to read real quotes from published authors.

Submit your manuscript here: http://www.dovepress.com/vascular-health-and-risk-management-journal 